\title{
Enforcing the Global Economic Order, Violating the Rights of the Poor, and Breaching Negative Duties? Pogge, Collective Agency, and Global Poverty
}

\section{Bill Wringe}

\section{Introduction}

Thomas Pogge has argued, famously, that "we" are harming the global poor. Indeed, we are not only harming them; we are violating their rights insofar as we uphold an unjust international order which provides a legal and economic framework within which individuals and groups can and do deprive such individuals of their lives, liberty, and property. ${ }^{1}$ The rights we are violating are ones whose existence Pogge takes to be relatively uncontroversial: rights to life, property, free assembly, and the like, rather than so-called "subsistence rights" whose existence is sometimes taken to be more controversial. ${ }^{2}$ Pogge also holds that in violating these rights, we are failing to fulfil duties: not simply positive duties, such as duties of assistance, but also negative duties, like the duty not to kill, or the duty not to endanger life. In an arresting image, Pogge suggests that our relationship to the world's poor is not like that of a passer-by who fails to come to the assistance of a victim of a hit-and-run accident perpetrated by another driver, but more like that of someone who is (at best) culpably negligent in causing an accident, and then fails to do anything to remedy the situation. ${ }^{3}$

In this article, I shall be primarily concerned with what I shall call the "Negative Duty Claim":

$\mathrm{N}$ : We are violating a negative duty by upholding the existing global order.

$\mathrm{N}$ constitutes a distinctive contribution to debates about moral responses to poverty. Although one's views about $\mathrm{N}$ do not settle every question in this area, accepting $\mathrm{N}$ appears to have the potential to transform our response to these questions. One conspicuous way in which it does so is by making the issue of our response seem more psychologically urgent; violations of negative duties are often seen as in need of, and therefore as justifying, more immediate and potentially more costly remedial action than failure to act in accordance with positive duties.

$\mathrm{N}$ is distinctive for a further, less widely discussed reason: the first-person plural mode of address that it incorporates. ${ }^{4}$ Pogge typically formulates his position as a view not about the actions and responsibilities of this or that group 
of individuals, of whom he and/or his readers may or may not be members, but by using the immediately arresting pronouns "we" and "us." Pogge's use of the first-person pronoun generates a sense of psychological urgency which goes beyond that suggested by his formulation of his claim in terms of negative duties. It does so, I suggest, precisely because it seems to invite an engaged response in the listener: one which leads them to expect that an appropriate response on the part of a listener will be one which demands something from them as an individual. ${ }^{5}$ This is true even though, or perhaps even because, there seems to be a certain amount of indeterminacy involved in the question of who exactly counts as "one of us." 6

One central claim in what follows will be that it is at this very point that Pogge overreaches. It is natural to assume that if "we" are violating the rights of the worst off, and if I am one of "us," there is something which I am morally bound to do in response. But I shall argue that we should resist this assumption. If there is a sense in which "we" are harming the worse off-and I shall suggest that there is, albeit one which most discussion of Pogge's views seems to have overlooked - then it is one on which very few claims about what $I$ should do can be straightforwardly inferred from the truth of $\mathrm{N}$.

My discussion will differ from many of those to be found in the existing literature by taking Pogge's claim about what "we" are doing to be a claim about collective action, rather than mere causal contribution to harm. ${ }^{7}$ Pogge himself suggests a reading of this sort when he speaks, in a recent article, of our violations of the rights of the world's poor being the result of something we "collaboratively impose." However, Pogge has said very little about this aspect of his position, or about how it might relate to existing accounts of collective action, collective obligation, and collective responsibility, and most existing discussions of his view do not engage with these issues.

This is unfortunate. As I shall argue in Sections V and VI, the collective agency reading of Pogge's position is both more textually plausible and more philosophically fruitful than the causal contribution reading-even though it cannot, in the end, sustain the results that Pogge apparently wishes to establish. I shall also argue, in Sections VII-XI, that on the collective agency reading of N, there is a sense in which it is plausible that "we" are upholding the global economic order and violating the rights of the least well-off. However, this sense is a nondistributive one, on which it does not follow that $I$ am upholding the global economic order or violating the rights of the least well-off. Furthermore, as I shall argue in Sections XII-XVII, there are no straightforwardly acceptable principles that would enable me to derive claims about ways in which $I$ am liable from the truth of the defensible reading of $\mathrm{N}$.

One might regard it as a mistake to attribute to Pogge even an implicit commitment to the view that $\mathrm{N}$ should have some action-guiding consequences for individuals. Pogge is often identified as favoring institutional over individualist responses to problems of global distributive justice. So we might think that he would be vindicated provided the claim that we are violating a negative duty 
entails that we should do something about it, whether or not this has any implications for what particular individuals should do. However, this line of thought conflates questions about what needs to be done with questions about who should do it. These are distinct issues, which are worth keeping separate.

Call a proposal "individual-focused" if it proposes to combat problems about international justice by effecting changes in individual behavior, and "institution-focused" if it does so by proposing changes not in individual behavior but in the structure of institutions. Pogge's approach to questions about global justice is institution-focused. But it does not follow from this that its addressees are, in the first instance, institutions. ${ }^{8}$ For it is individuals rather than institutions who read books such as Pogge's; and institutions can only be changed by individuals. If Pogge were putting forward an account which was not merely institution-focused but also addressed to institutions we might be able to be content with an account that had implications for the obligations of groups but not of individuals. ${ }^{9}$ But an account of that sort would hardly be one for which the first-person-plural mode of address was appropriate. And, in any case, we shall see that the institution that Pogge would need to be addressing with his "we" is a somewhat inchoate one.

\section{Preliminary Clarifications: Picking out the "We"}

I take $(\mathrm{N})$ to have two components. The first is a nonmoralized claim about what we are doing: namely, upholding the existing global order. The second is a claim about the moral significance of what we are doing: namely that our upholding of the existing global order constitutes a violation of a negative duty. Call these two components N1 and N2, thus:

N1: We are upholding the existing global order.

N2: In virtue of the truth of N1, we are violating a negative duty.

Neither N1 nor N2 refer directly to violations of rights. Nevertheless, Pogge makes an important claim about rights that is closely related to N1 and N2.

R: By upholding the existing global order, we violate the rights of the global poor.

For ease of exposition I shall sometimes refer to N1, N2, and R as the "Upholding Claim," the "Negative Duty Claim," and the "Rights Claim," respectively. On Pogge's view, the truth of R explains why N2 follows from N1. There may be ways of arguing from $\mathrm{N} 1$ to $\mathrm{N} 2$ that do not rely on the truth of R, but a view which relied on an argument of this sort would be significantly different from Pogge's.

Since Pogge frames his discussion of $\mathrm{N}$ in first person plural terms, it is natural to ask who is included when he talks about "us." This is sometimes 
unclear. ${ }^{10}$ Initially plausible-seeming answers include "everyone on the planet"; "every mature citizen of a Western democratic state"; "everyone in the actual or potential audience or readership of Pogge's talks and books"; and no doubt several others. Pogge himself has recently written as follows: "By 'we', I mean citizens of developed countries (e.g., the United States, the European Union, Japan, Canada, Australia, and New Zealand) who have sufficient mental maturity, education, and political opportunities to share responsibility for their government's foreign policy and for its role in designing and imposing supranational institutions." "11 While this seems clear enough, Pogge then obscures matters once more by saying that he "suspends judgment" as to whether "a laid off steel-worker or struggling single mother in today's United States" shares the responsibilities that he takes to follow from the truth of N. ${ }^{12}$

One reason why there is some unclarity about who Pogge's "we" includes is that it is not obvious which citizens we should take to share responsibility for their government's foreign policy. One might naturally regard possession of the right to vote as at least a necessary condition of such responsibility. On this view, Pogge's "we" would not include_-for example_-disenfranchised felons in some American states, or citizens of the United Kingdom who have not been resident in the United Kingdom in the last fifteen years (and have not acquired citizenship elsewhere). However, Pogge's discussion of the workers of Manchester who joined the anti-slavery movement in 1787 suggests that he might not accept possession of the right to vote as a necessary condition of the responsibility he is concerned with here. For although many of these workers would not have possessed this right — and certainly no women workers did-Pogge takes seriously the possibility that they would have been correct in taking themselves to have such responsibilities. ${ }^{13}$

One point is especially worth noting here. However, we interpret Pogge's remarks, it seems that his "we" will not include everyone who participates in the global economy, or whose actions contribute causally to the global economic order. For that class will include many people who are not citizens of developed countries: for example, residents of developed countries who are not citizens of either their country of residence or of any other country; and residents whether citizens or noncitizens, of nondeveloped countries who do not hold citizenship of any developed country. As we shall see in Section IV, this point will have significant consequences for the interpretation of $\mathrm{N} 1$.

\section{Preliminary Clarifications (2): Forward and Backward-Looking Responsibility and Accountability}

In discussing N2 I shall be primarily concerned with what is sometimes called "backward-looking" rather than "forward-looking" responsibility. ${ }^{14}$ This may surprise some readers. Pogge is concerned, with good reason, with the question of how the position of the world's poor might be improved. So we might expect him to be primarily concerned with the questions about "forward- 
looking responsibility": that is, with questions about who the burdens of alleviating the ills of the global poor might fall on. And Pogge sometimes addresses matters in precisely these terms. ${ }^{15}$ However, claims about what we have done, and in particular claims about violations of negative rights seem to be more naturally understood as claims about backward-looking responsibility: they are, after all, claims about who has done-or who is doing - what.

The apparent tension between these perspectives can be resolved if we take Pogge to be committed to a fairly natural, and initially plausible, way of connecting backward- and forward-looking responsibility, suggested by his discussion of the hit-and-run car accident, which I call the "Natural View." On the "Natural View," those who bear backward-looking responsibility for harms caused by violations of human rights thereby acquire-in the typical case, and other things being equal-forward-looking responsibilities for bearing the burdens involved remedying those violations. ${ }^{16}$

This formulation of the Natural View is an exegetical suggestion about Pogge's position, rather than a claim I take myself to be committed to defending. For my purposes, what matters is that if something like the Natural View is correct, then it explains why someone concerned with alleviating the situation of the world's poor should be interested in the truth of the Negative Duty Claim. But the exegetical suggestion would be uninteresting if it imputed an obviously untenable view to Pogge. Some further commentary is therefore necessary in order to forestall objections on this score.

It is important to notice that the Natural View, as I have stated it, has two parts: it provides a way of determining the bearers of forward-looking responsibility for remedying harms (on the assumption that some facts about backwardlooking responsibility are known); and it also specifies a direction of explanatory priority. ${ }^{17}$ The view thus excludes the-dubiously coherent—possibility that one might become retrospectively responsible (in the backward-looking sense) for past wrongdoing by taking on the burdens involved in remedying it. ${ }^{18}$

The qualifications "in the typical case," "other things being equal," and "in the first instance" are important elements of the Natural View. A version of the Natural View which omitted them would have implausible consequences: it would rule out the possibility of principles distributing what are sometimes called "secondary remedial responsibilities"- that is to say, responsibilities for compensating individuals for violations of rights in situations where those who had committed those violations were either unable to compensate for them or were in some way or another fully or partly morally excused from the burdens involved in doing so. In particular, it would entail-as the provisoed version of the Natural View which I have put forward does not - that violations of human rights committed by those who subsequently became unable to bear the costs involved in violating them should go uncompensated. ${ }^{19}$

Backward- and forward-looking responsibility should be carefully distinguished from a further notion with which they both, nevertheless, have at least something in common. This is the notion of accountability developed by 
Christopher Kutz. ${ }^{20}$ On Kutz's usage, accountability is at least in part a backward-looking notion: one is accountable (or not) for things that have happened in the past. But the notion also has a forward-looking dimension: those who are accountable for some wrongdoing are those who are liable - in the first instance-for the costs involved in reparative action.

This forward-looking dimension of accountability leads Kutz to place as a constraint on the acceptability of a theory of accountability that it should not allow for any "accountability gaps": situations where some serious harm has been done, but for which no individual is accountable. This feature of Kutzian accountability suggests that it is conceptually distinct from, and differs in its extension from the more familiar notion of backward-looking responsibility. Many theorists of backward-looking collective responsibility have been motivated to argue for the existence of collective responsibility precisely on the grounds that there appear to be cases where harm has been done, but in which no individual can be held responsible. If this is correct, then findings of accountability may go wider than findings of responsibility. ${ }^{21}$

Despite the differences between the notions of responsibility and accountability, the latter notion will prove to be of interest in what follows, insofar as it suggests a route independent of that established by the Natural View, by which facts about what we do together can have implications for what individuals will do. This will turn out to be of particular significance in the light of a key claim in this article-namely that the most defensible readings of the Upholding, Negative Duty, and Rights claims are ones that involve nondistributive forms of predication. For it will suggest a route-albeit an ultimately unsuccessful oneby which Pogge might attempt to show how these nondistributive claims might have significant action-guiding implications for particular individuals.

\section{Ambiguities in N: Distributive and Nondistributive Predication}

Pogge's discussion of $\mathrm{N}$ is framed in first-person plural terms: it involves claims about what "we" are doing. There are important questions about how claims of this sort are to be understood. It will be helpful to start by noting two related ambiguities that they may involve. One arises from a distinction that applies, in principle, to all cases where a predicate is applied to a plural subject term. Some such predications are, as logicians put it, "distributive." In such cases, it follows from the claim that "The $a$ s are F" that each individual $a$ is F. If I say, of a group of football fans that they are jubilant at their team's performance, I may mean that each of them is jubilant. Importantly for our purposes, not all instances of plural predication are distributive: if the football fans are appropriately jubilant because their team has outscored the opposition, it need not be true that each member of their team has outscored the opposition. ${ }^{22}$

The distinction between distributive and nondistributive forms of plural predication has significant implications. Consider N2, the Negative Duty claim. If we understand it distributively, then it follows from its truth that $I$ am 
violating a negative duty. And if we accept something like the Natural View, it will follow fairly straightforwardly that I have good reason to take myself to be responsible for bearing the costs of remedying the wrongs that this violation of a negative duty brings about. But if we understand $\mathrm{N} 2$ nondistributively, matters will be less clear. For on this reading, N2 can be true even if it is not true that $I$ am violating a moral duty. So, even if the Natural View is correct, it will not follow so straightforwardly that I am responsible for bearing these costs. ${ }^{23}$

We might nevertheless wonder whether a conclusion of this sort can be taken to follow in a less obvious fashion. For example, we might take it to follow from the truth of $\mathrm{N} 2$, read nondistributively, together with the natural view, that we are responsible for bearing the costs of remedying our violations of negative duties. But again, the distinction between nondistributive and distributive forms of plural predication seems important. Unless we read this claim about forward-looking responsibility in a distributive manner, it will still not follow that $I$ am responsible for bearing any costs. Furthermore, there seems to be some mystery involved in inferring from a nondistributive version of the Negative Duty claim and the Natural View to a distributive claim about forward-looking responsibility. ${ }^{24}$

It is tempting to take Pogge to be committed to a distributive reading of N1, since he seems to take $\mathrm{N} 1$ to have some implications for the forward-looking responsibilities of the individuals he is addressing. However, we should be cautious about this inference for at least three reasons. First, Pogge rarely seems to commit himself to the truth of distributive versions of claims like R: he refrains from claiming of each individual that he is addressing that they are violating the rights of the world's poor. ${ }^{25}$ If Pogge's view is compatible with the possibility that $\mathrm{R}$ is true only in a nondistributive sense, then we should also bear in mind the possibility that is compatible with N2's being true only in a nondistributive sense. Second, taking the truth of N2 to have implications for the forwardlooking responsibilities of Pogge's "we" does not require us to understand N2 distributively. For one might in principle argue from the backward-looking responsibilities of a group of people to the existence of forward-looking responsibilities falling on members of that group in any number of ways (e.g., by arguing from nondistributive backward-looking responsibilities of the group to forward-looking responsibilities of the group, and then from forward-looking responsibilities of the group to forward-looking responsibilities of members ${ }^{26}$ ).

Finally, and most importantly, the question of whether we should understand N2 distributively or not seems likely to depend on how N1 is understood. Like N2, N1 will admit of both distributive and nondistributive readings. In this section and the next, I shall argue that the most plausible reading of N1 is a nondistributive one. This reading of N1 which I call the "collective agency" reading, is one on which the most straightforward inferences of N1 to the truth of some version of R and thence to some version of $\mathrm{N} 2$ are likely to involve nondistributive versions of those claims.

Does $\mathrm{R}$ admit of nondistributive readings? If we think that any claims about rights violations admit such readings, it is hard to see why $\mathrm{R}$ should not. And 
provided we think that collective agents can violate rights, we have reason to think that at least some claims about rights violations should be read nondistributively. ${ }^{27}$ Or at least we will have such reason provided we think that an agent who violates a right thereby acts wrongly. For it seems possible for an individual to be a member of a rights-violating collective agent under conditions which excuse the individual from wrongdoing. One obvious example would be when an individual's membership of the collective agent that violates rights is coerced. Another might be when an individual's membership of a given collective agent persists despite the existence of conditions which would typically excuse them from wrongdoing more generally, such as excusable ignorance of or inattention to the nature of the course of action pursued by the collective of which they are a member was performing. Under these circumstances the individual who is excused does not act wrongly; and if the connection between rights violation and wrongdoing that I mentioned earlier can be sustained, they do not violate any rights.

In arguing for the intelligibility of nondistributive readings of claims about rights violations I have drawn on very general claims about collective agency and rights violation (such as the fact that collectives may contain members who are for one reason or another excused from wrongdoing perpetrated by their members, and that collective agents may have options which are deliberatively available to them, but not to their members). The generality of these considerations suggests that claims about rights violations committed by collective agents should typically be understood to involve nondistributive predication. However, the fact that a certain claim involves nondistributive predication is only a fact about what that claim entails - that is to say, a claim about what is true in all possible worlds where the claim is true. So it is compatible with everything that I have said that in any given case, a collective agent can be guilty of violating someone's rights and that every individual member of that collective should be guilty of violating that individual's rights.

\section{Ambiguities in N1: The Causal Contribution and Collective Agency Readings}

$\mathrm{N} 1$ admits of both distributive and nondistributive readings. I shall now argue that we should focus on the nondistributive reading. To see why, it will be helpful to consider a further ambiguity in N1 between what I shall call the "causal contribution" and "collective agency" readings. On the "causal contribution" reading, N1 will be true just in case each of the individuals included in Pogge's "we" plays makes some causal contribution to upholding the global economic order. Call this claim N1cc. On the "collective agency" reading of $\mathrm{N} 1$, it will be true provided that the "we" whom Pogge is addressing constitute some kind of collective agent, which upholds the global economic order. Call this claim N1ca. 
N1cc and N1ca are not equivalent. On almost all accounts of collective action, the truth of N1cc will not be sufficient for the truth of N1ca. ${ }^{28}$ We can see this by noting that on most accounts of collective action, some things that are the upshot of actions on the part of a plurality of individuals will not count as instances of collective action. For example, on many such accounts, if passers-by wear a path in some grass without coordinating their actions in any way, but simply in virtue of the accumulating effects of the footsteps of one person after another, this will not count as an instance of collective action. What more is required will vary from theory to theory: it may be an intention to participate in a common project ${ }^{29}$; a collective or corporate decision procedure ${ }^{30}$; a joint commitment, ${ }^{31}$ or something else. (On many accounts N1cc may also not be necessary for the truth of N1ca either: it may be compatible with some members of the "we" making no causal contribution, or making a causal contribution which is counteracted or pre-empted by the contributions of others.)

N1ca seems to involve a nondistributive form of collective predication; for, typically and on most plausible theories of collective agency, what is true of collective agents will not be true of the individuals that makeup that collective. ${ }^{32} \mathrm{I}$ shall argue in Section VI, we should adopt the collective action reading of N1. It follows that we should read N1 nondistributively. ${ }^{33}$

\section{Against the "Causal Contribution" Reading}

N1cc has been the focus of a recent debate between Elizabeth Ashford and Saladin Meckled-Garcia. ${ }^{34}$ Central to this debate has been the question of the plausibility of the inference from N1cc to R, and thence to N2: Ashford claims, drawing on work by Derek Parfit and others, that an inference of this sort is valid. ${ }^{35}$ Meckled-Garcia denies this. This debate has been somewhat inconclusive: it appears to turn on the plausibility of a principle which Meckled-Garcia affirms and Ashford denies, to the effect that nonfulfillment of an individual's rights can only constitute a rights violation if it is the result of an action by some specifiable agent or agents.

It is not clear whether Pogge intends N1 to be understood along the lines of N1cc. Understanding it thus fits poorly with an aspect of Pogge's position which I noted in Section II: namely, that Pogge's "we" excludes many individuals who contribute to the global economy. This exclusion is difficult to motivate if Pogge intends N1 to be understood along the lines of N1cc. It also seems somewhat patronizing: why should Pogge address his message only to the citizens of developed countries and not to others who make a causal contribution? N1cc would remain true if we took Pogge's "we" to extend to those individuals. ${ }^{36}$

Some might suggest that there is no point in Pogge addressing these individuals with his "we": they are either politically or economically disempowered to such an extent that it is unlikely to be worthwhile addressing claims such as N2 to them. But this seems implausible: a relatively wealthy citizen of an underdeveloped 
country seems at least as empowered in this respect as the eighteenth-century Manchester machine-workers mentioned in Section II can have been.

N1ca seems, then, to accord better with Pogge's own formulation of his position. ${ }^{37}$ It also suggests a way of circumventing the debate between Meckled-Garcia and Ashford. To see this, it will be helpful to see why, on Meckled-Garcia's view, the inference from N1cc to R fails. Suppose N1cc is true, and suppose that it is also true that, as a result, many of the world's poor live in a situation in which their human rights are unfulfilled. Even under these assumptions, it does not follow that anyone's rights are being violated; and if no one's rights are being violated neither we nor anyone else is violating anyone's human rights.

Pogge would not dispute this. As far as he is concerned, there are at least two further conditions that must be true for human rights violations to be occurring: they must be foreseeable, and they must be avoidable. ${ }^{38}$ The notions of foreseeability and avoidability are complex ones: they refer to capacities which, on some views of things, only agents can have, and which can only be applied to groups containing more than one person when those groups constitute a collective agent. ${ }^{39}$ However, Pogge seems to have in mind something weaker than this when he talks about the nonfulfillment of human rights being "avoidable." He seems to mean that there is a set of actions (or perhaps several sets of actions) that could be taken by identifiable agents, and on which the nonfulfillment of these human rights would not occur. Let us grant that this is in fact the case.

Does R follow from the truth of N1cc and the fulfillment of the foreseeability and avoidability conditions that human rights are being violated? MeckledGarcia thinks not. He argues that human rights violations must involve what he calls "directed wrongdoing" by some agent or agents. For an action or omission to commit "directed wrongdoing," he claims, it must "unreasonably impose a loss or risk on some person." An action can only impose a loss or risk "unreasonably" if there is some reasonable principle available to the agent whose adoption would prevent risks or losses of this sort. A principle can only count as "available" to an agent in this sense if it is a principle that the agent could actually adopt in the world as it is. ${ }^{40}$

In some situations, one can contribute causally to the nonfulfillment of human rights without committing any directed wrongdoing. For there are situations where there is no reasonable principle on which I might act which avoid these consequences. We might think that at least some of the actions by which I uphold the global economic order fall into this category. For example, it is arguable that on Meckled-Garcia's conception of reasonableness, I do not unreasonably impose losses on the world's poor simply by participating in the global economy. For there is no reasonable principle available to me, on which I can avoid participating in the global economy. If this is correct, the truth of $\mathrm{R}$, and hence of $\mathrm{N} 2$ do not follow from N1cc.

One might respond to this line of argument by disputing the claim that rights violations must involve directed wrongdoing. ${ }^{41}$ Or one might accept this 
claim while arguing that Meckled-Garcia's account of reasonableness is too narrow. ${ }^{42}$ For example, one might take a principle to be reasonable if a group of agents could adopt it together, even if no individual agent could adopt it on their own. If this conception of reasonableness is adopted then the possibility of alternative global economic orders which do not inflict the kinds of harm that are currently inflicted on the global poor, would leave open the possibility that these harms are in fact "unreasonably imposed" and do, for that reason, constitute directed wrongdoing. ${ }^{43}$

One difficulty in resolving the debate between Meckled-Garcia and Ashford is precisely this framing in terms of "reasonableness." For it is not clear whether this notion is sufficiently substantial for debates about what is and what is not reasonable to be clearly resoluble. However, switching our attention from N1cc to N1ca suggests a way out of this impasse. For in order to block the inference from N1cc to R, Meckled-Garcia needs to claim that there is no specifiable agent to whom the rights violation in R could be attributed. But on many-though not all-theories of collective agency, the truth of N1ca will require the existence of a collective agent of precisely the sort that Meckled-Garcia takes to be missing on Ashford's view. Since, as I have already argued, N1ca is also a more plausible reading of $\mathrm{N} 1$ on textual grounds than $\mathrm{N} 1 \mathrm{cc}$, we should concentrate our attention on this way of understanding Pogge's view.

\section{The Collective Action Reading of N1 and N2}

In Sections III and IV, I distinguished between the "causal contribution" and "collective agency" readings of N1, and gave both textual and philosophical reasons for focusing on the latter. This raises a problem. Although philosophers have given a number of different accounts of collective action in recent decades, Pogge himself has given no indication as to the conception of collective agency he thinks might be most relevant to understanding his view. ${ }^{44}$

We can distinguish two different approaches to philosophical discussions of collective action, which I shall describe as "singularism" and "pluralism." On a "singularist" view, different accounts of collective action should be regarded as rival, and mostly incompatible accounts of a single core phenomenon that constitutes some kind of overarching social or metaphysical kind. On a "pluralist" view, there are a number of related phenomena, all of which might legitimately be regarded as phenomena of collective agency, and which might be more or less closely related to one another. ${ }^{45}$ In what follows I shall remain agnostic as to whether a singularist or a pluralist approach to collective action is correct while approaching matters from a pluralistic perspective for expository purposes. ${ }^{46}$

Accounts of collective action can be ordered in terms of how much internal organization in a group they take to be required for collective action to be possible. At one end of the spectrum are views like Christopher Kutz's on which the conditions for collective action are comparatively easily met. ${ }^{47}$ On views of this sort it is relatively easy to show that a group of individuals have engaged in some form of 
collective action. At the other end of the spectrum, there are accounts such as Peter French's, which require a high degree of organization within a group. ${ }^{48}$

For ease of reference I shall sometimes refer to Kutz's model and French's model as the "minimal" and "corporate" conceptions of collective action. However, it may be worth noting that when I talk about the "corporate" conception of collective action, I shall not always have in mind literal business corporations, as defined by the legal system of the United States or any other country, of the sort which French focuses on. Rather, I use the label "corporate action" to refer to a particular way of conceiving of collective action, which is modelled on French's notion of corporate action (and which I shall explain and motivate in more detail in Section IX.) ${ }^{49}$

In what follows, I shall examine views at each end of the spectrum of demandingness, and argue that neither of them provide us with what Pogge's position seems to require: namely, an account which makes it plausible that "we" make up a collective agent that acts in a way that violates a negative duty, and which also grounds ascriptions of liability to individuals. ${ }^{50}$ Of course, this leaves open the possibility that some account intermediate between Kutz's and French's might in principle do the job that Pogge requires. However, it seems reasonable to think that if neither of these two accounts can do the job, the onus is on Pogge to propose one that will.

\section{Kutz's Minimalist Account of Collective Action}

Christopher Kutz's minimalist account allows for the possibility of collective action occurring in relatively unstructured groups. On a view of this sort, the claim that "we" are performing some action or engaged in some kind of activity is hostage to relatively few claims about how "we" are organized or relate to one another. A defense of $\mathrm{N}$ understood along Kutzian lines therefore seems likely to be compatible with a wide range of views about how the global economic order is enforced.

Central to Kutz's account is the notion of a "participatory intention." A "participatory intention" is an intention to carry out one's role in some kind of collective project. The project involved may be either small-scale — such as playing a game of chess — or large-scale — such as participating in the firebombing of Dresden. ${ }^{51}$ A person can have a participatory intention without necessarily having any detailed knowledge of the roles that other individuals need to play in order for the collective project to succeed; and they may even have one if they are unsure about some of the details of what the project aims at achieving. So, for example, I might have a participatory intention relevant to my involvement in the firebombing of Dresden without necessarily intending to carry out a large-scale terror attack on a civilian population: I might simply intend to do my duty by having the intention to play my part in what I think of as the military exercise scheduled to take place at such and such a time and in such and such a place.

On Kutz's account, it is a necessary and sufficient condition for my participation in a collective action that I have a participatory intention of the right sort. 
One might object that this cannot be an analysis of the notion of collective action, since the definition of a participatory intention seems to involve reference to the notion of a collective action. However, Kutz argues that this need not matter: we do not need an analysis of the notion of collective action in order to know the truth-conditions of the claim that I have participated in something that we have done. ${ }^{52}$

Does Kutz's account entail that we are upholding the global economic order? Kutz himself suggests that we can usefully be seen as participating in a collective economic project by virtue of participating in a market economy: by buying and selling, accepting paid employment, and so on. The claim that we are upholding the global economic order might seem to go beyond this in two respects. Someone might suggest that our participation in a market economy need only require an intention to participate in a local-rather than global-economic project. Alternatively, they might draw a firm distinction between participating in an economy under a given set of rules and upholding those rules.

The first of these points seems easily answered. While there presumably could be a functioning global economy whose participants were simply ignorant of the existence of economic relationships above the national level, most reasonably (or even minimally) well-informed consumers will be aware of some of the international dimensions of trade and employment relationships: they will know that many of the foods they eat are produced abroad, and that the electronic goods they purchase will have been manufactured in other countries before being distributed in a range of different countries, and so on. The second point is slightly trickier to handle. Economic participation need not entail an awareness of the rules by which international trade is governed, let alone an intention to participate in a project of setting those rules.

One strategy would be to suggest that what is important in this context is not whether one intends to participate in a certain project, but whether one benefits from doing so. However, this line of argument would take us outside Kutz's framework. A response which fits better with that framework, and which would make sense of Pogge's remarks about his intended audience discussed in Section II, would be to suggest that political, rather than economic, participation might indicate involvement in such a project. For while many enfranchised citizens will not be aware of the details by which the terms of trade between different nations are set, they will at least be aware that the politicians they elect will have as part of their role that of negotiating acceptable, and as far as possible advantageous, terms of trade for the citizens of their own countries.

So on Kutz's account N1 seems to be true. That is to say, it seems true that

N1: We are upholding the existing global order.

where this is interpreted, along lines that I have already suggested in Sections IV-VI, as a claim about collective action. 
By contrast, Kutz's account does not provide a straightforward way of defending R:

R: By upholding the existing global order, we violate the rights of the global poor.

It seems implausible that my participating in the domestic politics of my own country need entail that I intend to participate in a project which I frame to myself as being that of violating the rights of the world's worst-off. (Some people may frame things to themselves in just this way, priding themselves on their hardheaded realism. But it need not be the general case.) Still, one might be tempted to think that if N1 is true and the workings of the global economic order result in the rights of the global poor being unfulfilled, then $\mathrm{R}$ must be true as well.

However, we saw in Section VI that there are reasons for resisting inferences from claims about the nonfulfillment of human rights to claims about the existence of violations. We saw in that discussion that a great deal turned out to depend on how we understood the notion of reasonableness that MeckledGarcia appealed to in attempting to block that inference. We might wonder whether Kutz's account of collective agency provides us with some way of bridging the gap that Meckled-Garcia identifies between rights going unfulfilled and rights being violated.

One way in which we might hope it could do so is by identifying some collective agent which could plausibly be seen as a violator of rights even when no individual can plausible be so seen. (Such an agent would have to be something of which we could intelligibly ask whether it adopted principles that were, on Meckled-Garcia's conception of reasonableness, "unreasonable.") However, Kutz's account cannot help us in this way. For Kutz emphasizes that his account is "metaphysically lightweight": it is intended to explain the possibility of collective action in a way that does not entail the existence of any collective agents. ${ }^{53}$ If we want to argue that in upholding the global economic order, we are violating the rights of the global poor, we will have to find another way of doing so. And insofar as claims about violations of duties are supported on the basis of claims such as R, Kutz's account gives us no reason to accept them. Such claims include N2:

$\mathrm{N} 2$ : In virtue of the truth of $\mathrm{N} 1$, we are violating a negative duty.

\section{Collective Action and Corporate Action: French's Model}

Let us instead consider what I labeled in Section VII a corporatist model of collective action. Peter French has explored the relationship between collective action, conceived of as corporate action, collective responsibility, and individual 
responsibility in some detail. ${ }^{54,55}$ On his account it is appropriate to talk of collective action in cases where we have a body in which we can identify a corporate decision structure that enables us to say which decisions taken by individual members of the corporation should count as actions of the corporation. ${ }^{56}$ Typically, the corporate decision structure will be one that enables us to identify some of the organization's goals or desires, and also its beliefs. The actions of the corporation will be actions carried out by its members in ways which accord with the requirements of the decision structure. ${ }^{57}$

It might initially seem implausible to think that any of the groups of individuals that Pogge wants to pick out with the pronoun "we" has anything analogous to a corporate decision structure. They are widely scattered across different nations and continents, and need not regard themselves as being part of a single organization. ${ }^{58}$ Furthermore, the ideas of a corporation and of a corporate decision structure seem to be defined by reference to the legal system of a particular state. If so it is not clear that we can make sense of the idea of a global corporate decision structure of the sort which Pogge would need to appeal to here.

However, the idea may be less far-fetched than it initially seems. It is certainly plausible that individual states are capable of corporate action in ways that are roughly analogous to the ones provided for by French's account. We might see the constitutions of some states as providing something analogous to a corporate decision structure. ${ }^{59}$ We might also want to loosen the requirement that a corporate decision structure be formulated in a fully explicit manner to allow for the possibility of states such as the United Kingdom having such a structure. ${ }^{60}$ Finally we might see international law as providing a framework that enables us to identify certain individuals performing certain roles as being the executive officers of the state. ${ }^{61}$

This does not yet give us anything that we could regard as an international collective agent of the sort that Pogge has in mind when he discusses the harms that he claims we inflict on the global poor. Still, the account might be developed further. Pogge often emphasizes the ways in which international organizations, treaties, and conventions defining international legal roles play in contributing to the sorts of harms with which he is most concerned. These institutional frameworks could be seen as the collective work of the sovereign states of the world: the work, in other words, not of an individual collective, but of a collective of collectives. For this account to be workable, it seems as though we would need to think of there being a corporate decision structure defining the conditions under which the actions of states could be seen as constituting acts of the international community.

There are several reasons for being skeptical about whether an account of this sort would enable Pogge to defend a nondistributive version of his accusation. First of all, it is not clear how many acts of states, if any, could be regarded as proceeding from an international decision structure of the sort that this account envisages. Of course, there are international bodies, such as the United Nations, which might be regarded as acting for an international community in 
the way that this account envisages. However, the sorts of economic arrangements on which Pogge-rightly-tends to focus his attention do not seem to come into existence as the result of decision making carried out in this way but as a result of a rather more haphazard system of negotiation whose outcomes typically reflect in a somewhat ad hoc manner the balance of power between different states rather than the operation of some predetermined and formalized means of making decisions. ${ }^{62}$

Still, it might be argued that, to the extent that such negotiations are typically conducted within and enforced by reference to the decisions of an international institutional framework, this framework can be seen as providing something which is sufficiently similar to a corporate decision structure for something like French's model to apply. ${ }^{63}$ On the account envisaged, in saying that "we" are violating the rights of the global poor, we are attributing an action to a highly complex kind of collective agent. It is a collective agent that is composed, at least in the first instance, not of individual human agents but of other collective agents which are themselves composed of individuals.

\section{Revisiting R: A Collective Agency Defense}

In Section IX, I argued that the individuals that Pogge picks out with his "we" might be seen as constituting a complex collective agent, whose actions might include upholding the global economic order. In other words I have argued that on this account it is true that

N1: We are upholding the existing global order.

This approach to defending N1 has limitations. For example, it is not clear exactly which actions can be attributed to "us" on the model proposed. French's account is designed to solve the problem of deciding which actions performed by individuals associated with a certain collective body can be attributed to that collective and which cannot. Answers to questions of this sort will depend both on the details of the corporate decision structure of the institution in question, and the details of how any particular decision got made.

Something similar will be true when it comes to deciding exactly which actions can be attributed to the international community. If we are not simply interested in showing that we can make sense in theoretical terms of the idea that "we" are committing such rights violations, but in determining in precisely which cases we are guilty of doing so, then we will need a careful delineation of what exactly the global analogue of the corporate decision structure is together with careful accounts of how particular decisions have come about. Although Pogge's work is studded with empirical data about the results of poverty, he provides us with very few case studies of the sort of decision making that would be needed to support attributions of responsibility in such cases. Still, we might see 
this less as an objection than as an important refinement that the collective agency reading of $\mathrm{N} 1$ forces on us.

However, a defense of $\mathrm{N}$ along the lines suggested faces a more significant obstacle. N2 goes beyond N1 insofar it makes a claim about wrongdoing. In Section II, I suggested that the gap between N1 and N2 might be bridged by a principle along the lines of $\mathrm{R}$.

R: By upholding the existing global order, we violate the rights of the global poor.

We now need to consider whether, on the account I have put forward, the way in which we uphold the global economic order could constitute a rights violation. In particular, we should ask whether the collective agent implicated in upholding the global economic order can count as violating rights.

In order to establish whether R might be true, we need to consider the following four conditions: whether the collective agent whose existence I argued for in Section IX makes a causal contribution to the nonfulfillment of the rights of the poor; whether that contribution is foreseeable; whether it is avoidable; and whether it constitutes a case of what Meckled-Garcia calls "directed wrongdoing." In each case the question we need to ask is a question about the collective agent considered in Section IX.

One point is straightforward. If we think that the global economic order contributes to the nonfulfillment of rights and we see this as the action of a collective agent, then we can see the collective agent's action as making contributing causally to the nonfulfillment of those rights.

What about the foreseeability and avoidability conditions? I suggested earlier that as far as Pogge is concerned, the question of whether the nonfulfillment of rights of a particular individual counts as foreseeable and avoidable need not be understood as the question of whether individual agents causally implicated in that nonfulfillment are capable of foreseeing or avoiding that nonfulfillment. If we adopt a similarly lax standard for foreseeability and avoidability at the collective level, then matters are straightforward. However, one advantage of the collective agency approach is that it puts us in a position to articulate and defend a more stringent standard for foreseeability-namely that the collective agent involved in the rights violations which are in question here can foresee and avoid the nonfulfillment.

Is the nonfulfillment of rights brought about by the collective that upholds the global economic order foreseeable and avoidable by that collective? There may be some difficulty in deciding how to apply the notion of foreseeability here. To foresee is, among other things, to hold a (well-grounded) belief about the future. So if we wish to apply the notion of foreseeability here, we will need to say something about what it is for the collective (as opposed to its members), to believe something. There is an extensive literature on the notion of collective 
belief. But one approach we might take is to take the role that belief plays in deliberation to play a central role in articulating the notion we need here. We might, in other words take the collective's beliefs to consist of those informational resources on which it is able to draw in deciding how to act. In asking whether the collective can foresee that in upholding the global economic order, it brings about avoidable rights violations we are asking whether the information that these policies will lead to the nonfulfillment of rights could come to play a role in its deliberations. It seems hard to see how someone even minimally sympathetic to Pogge's outlook could deny this. If the relevant information is available to individuals - as Pogge presumably takes to be the case-then it is presumably available to those individuals whose actions and decisions constitute the actions of the collective agent we are considering here.

One might perhaps deny this if one thought, for example, that international negotiators are formally precluded, by their role as negotiators, from considering anything other than the material interest of states on whose behalf they are negotiating - in something like the way that it's sometimes thought that the officers of business corporations are precluded from adopting aims other than that of maximizing shareholder value. However, while it is hard to deny that there will often - perhaps always — be very strong political pressures which make it difficult for them to consider the human rights impacts of their deliberations, it's difficult to accept that negotiators simply could not be moved in the right kind of way, not least since it seems at least possible that they could be authorized to take such considerations into account by those on whose behalf they are negotiating.

So much for foreseeability. What of avoidability? There is, of course, room for empirical disagreement as to whether there are feasible alternative forms of economic organization that would avoid the foreseeable nonfulfillment of human rights which moves Pogge. Still, there seem to be good reasons for thinking that some forms of structural change might do so. In recent work, Leif Wenar and has drawn attention to the way in which current political arrangements incentivize tyrannical rulers to appropriate the natural resources of weak states, and both he and Fabian Schuppert have suggested practicable reforms which might remove these incentives. ${ }^{64}$

This brings us back, once again to the issue of directed wrongdoing, and in particular the question of whether any of the actions of the collective agent we are considering might constitute "directed wrongdoing." Recall that on Meckled-Garcia's account directed wrongdoing must unreasonably impose harm or loss, and that an action only imposes harm or loss unreasonably if there is some principle available to the agent concerned which would prevent harms or losses of this sort. One might think that on this account of directed wrongdoing it is more or less impossible to show that upholding the existing economic order could constitute directed wrongdoing; one would presumably have to show that some alternative order is available on which no harms or losses of the kind imposed by the existing economic order took place. And this is, of course, a pretty tall order. 
However, the idea that directed wrongdoing requires the possibility of alternative courses of action which involve no similar losses seems implausible. What should we say about agents who choose courses of action that involve harms or risks while ignoring the possibility of alternative courses of action which involve fewer harms or losses, or smaller or less widely distributed risks? Some might deny that agents that pursue such courses of action act unreasonably. ${ }^{65}$ But this seems highly implausible. Suppose I am rushing someone suffering from a life-threatening medical emergency to hospital in a rural area, and I have a choice between two routes with equal travel times, one busy and one less so. Suppose that I decide to exceed the speed limit, thereby imposing a risk on some travelers, and suppose the gravity of the emergency is such as to make imposing risk on travelers on the less busy road reasonable. I nevertheless choose to take the busier road. It does not seem implausible to think I have imposed these risks unreasonably, even if the only other option available to me would have imposed risks on some individuals.

If this is right, then it will be much harder to argue that the collective agent we are considering avoids directed wrongdoing. Instead of showing that an alternative order is available on which no harms or losses of the kind imposed by the existing economic order took place, we simply need to show that an alternative order is available on which fewer risks or harms are involved. In other words, on this account the reasonableness component of the requirement that rights violations involve directed wrongdoing seems to add little to the foreseeability and avoidability conditions which we have already discussed.

However, we still need to consider a further condition that Meckled-Garcia builds into his account of directed wrongdoing. This is that an alternative course of action need to be "available" to the agent to whom the directed wrongdoing is imputed. At this point, a focus on collective agency leads to conclusions that differ significantly from those Meckled-Garcia himself reaches. Meckled-Garcia argues that from the perspective of individual agents involved in negotiating economic arrangements, alternative arrangements may not be "available." But it is not so clear that they are unavailable to the collective agent that we are considering. From the point of view of an individual agent, a course of action whose success depends on the contribution of others may not count as available to that agent. It may not be among their deliberative options. It may, nevertheless be among the deliberative options of a collective agent to whom those individuals belong.

It may seem mysterious how this can be the case. After all a collective agent can only pursue an option via the actions of individuals who make it up. However, the deliberative perspective of a collective agent can differ from that of individuals. An individual deliberator cannot, when considering which options are available, simply assume that other individuals will co-operate with him/her in ways that will bring about a desired outcome. But from the perspective of a collective agent this kind of worry disappears. We simply don't have a collective agent if there is no mechanism by which it can be brought about that 
individuals who need to act in a particular way for the collective agent to act in that way will actually do so. The mechanisms by which this can happen will be very various: they can include sanctions, psychological identification with the perspective of the collective, mechanisms of joint commitment, and so on. As a result, options that are not deliberatively available to individual members of a particular group may be deliberatively available to a collective agent. None of this need entail that the collective agent acquires mysterious powers to bring about changes in the world independently of the actions of individuals.

Someone might object that this cannot be right. Surely, they might say, a collective agent's success in carrying out its options depends on the cooperation of other agents, just as an individual's does. So the options that are deliberatively available to a collective agent cannot extend further than those deliberatively available to individuals who make up that agent. However, this objection seems to prove too much. If an option counts as unavailable for a collective agent whenever its success depends on the action of individual agents who are part of the collective agent, then no options will ever count as being available to collective agents. Insofar as an agent can only violate rights if some options are deliberatively available to them, it would appear to follow that collective agents cannot violate rights at all. This seems highly implausible. ${ }^{66}$

\section{Reading R Nondistributively}

The defense of $\mathrm{R}$ - and of $\mathrm{N}$ - which I have offered in Sections IX and X draws heavily on the idea that the "we" who are violating the human rights of the world's poorest do so as a collective agent. I argued in Section IV that we had good reason to take claims about rights violations committed by collective agents to involve nondistributive predication. So I now take myself to have argued for a nondistributive reading of $\mathrm{R}$.

To say that $\mathrm{R}$ is true in a sense which involves nondistributive predication simply means that the truth of $\mathrm{R}$ is compatible with the following claim:

S: Some of us do not violate the rights of world's poorest.

It does not follow from this that $\mathrm{S}$ is in fact true. And it does not follow that the truth of $\mathrm{R}$ is compatible with the truth of $\mathrm{S}^{*}$.

S*: No individual violates the rights of the world's poorest.

Still, some might worry that the nondistributive reading of $\mathrm{R}$ is compatible with $\mathrm{S}^{*}$. This worry has at least two sources. The first is that, it is at least not obvious that directed wrongdoing by collective agents need involve any directed wrongdoing by any of the individual agents who make up that collective agent. Furthermore, one might think that Meckled-Garcia has made a strong case for 
thinking that the actions by which the global economic order are imposed do not involve-or need not involve-any directed wrongdoing at the individual level. Since nothing I have said here undermines the case he has made for thinking this, it seems as though the question of whether the nondistributive reading of $\mathrm{R}$ is compatible with the truth of $\mathrm{S}$ remains open.

How serious a problem is this and for whom? It may well be a problem for Pogge. As I noted in Section I, the terms in which Pogge expresses his view suggest that the truth of $\mathrm{N}$ has some significance for how I should act. If the truth of $\mathrm{R}$ is compatible with the truth of $\mathrm{S}^{*}$ then one obvious route to this conclusion is blocked (I shall examine whether there are any other less straightforward routes to the same destination in Sections XII-XVII below).

Still, one might worry that the idea that R's truth could be compatible with the truth of $S^{*}$ is incoherent, since it seems to involve the possibility of a collective agent doing something which it is obliged not to do without any individual doing something which they are obliged not to do. Whether not this is possible is an issue that has been discussed in considerable detail in the literature on collective obligations. ${ }^{67}$ Fortunately, however, we do not need to take sides on this issue. For even those who argue that a collective can only do something it is obliged not to if some individual does something they are obliged not to do so in a way that leaves open the possibility that in doing so they need not have violated any rights. ${ }^{68}$

To see how this is possible, it is helpful to focus on one kind of case that David Copp has discussed in some detail. This is the case of a collective which makes a mistaken decision about the fate of an individual on the basis of a vote in which the members of the committee all have legitimate moral excuses for voting the wrong way. (The point of focusing on cases where individuals are excused from wrongdoing rather than compelled is that otherwise we may be inclined to conclude that the committee could not have decided otherwise than it did, and therefore was under no obligation to do so.) Let us also suppose that the committee's decision involves violating the rights of the individual about whom they are deciding. This rights violation must involve wrongdoing that is directed not (just) in the sense introduced by Meckled-Garcia and discussed in detail in this article, but in a more straightforward sense of wronging a particular individual. It must involve, in other words, the breach of a duty owed to a particular individual—namely the individual whose rights are violated.

Frank Hindriks and Stephanie Collins say of such cases that even if no one was at fault for voting as they did, it does not follow that no committee member has breached their obligations. For we might hold that individual committee members had a duty to institute procedures that would have prevented the kinds of outcome in question. (Alternatively, we may think of the collective agent as the body on whose behalf the committee is acting, and hold that those who set up the committee breached their obligations.) They also concede that such actions may be merely pro tanto rather than all-out duties. But we should notice that duties of this sort do not seem to be duties owed to the person whose rights 
are violated, and that they therefore do not constitute violations of the rights of the individual the committee violates.

Why should we think that the obligations that the committee members breach should not be regarded as directed obligations? One is that if an obligation has been breached in cases where the committee decides to act in a way that violates someone's rights, the very same duty would already have been breached before the committee's decision was made, and would still have been violated if for some reason the relevant decision had not needed to be taken. In this case the obligation that has been breached cannot be a directed obligation-there is no particular individual we can see the obligation as being directed to. But in cases where the committee does violate someone's rights it is the very same obligation that is breached. So it cannot be a directed obligation either, and a failure to fulfill it need not constitute a violation of anyone's rights (even though it may be a necessary condition of a rights violation occurring). In short, even if we agree that there can be no breach of a collective's obligations without some breach of an individual's obligations, it does not follow that any rights violation by a collective agent must involve some rights violation by an individual who is a member of that collective.

\section{Action-Guiding Implications for Individuals (1): A Corporatist Account?}

I have now argued for the truth of nondistributive readings of the following claims:

N1: We are upholding the existing global order.

$\mathrm{N} 2$ : In virtue of the truth of N1, we are violating a negative duty.

R: By upholding the existing global order, we violate the rights of the global poor.

The truth of these claims, so understood, might be taken as a vindication of Pogge's position. But as I noted in Section I, matters are not quite so simple. For Pogge's claims about what we have done are presented in such a way as to suggest that they have significant implications for the question of what each one of us should do. If distributive readings of N1, N2, and R could be defended, this conclusion would be not only natural but correct. But since only nondistributive versions of these claims can be defended, and since such claims, by definition, say nothing about whether any particular individuals have violated rights or breached obligations, nothing yet follows about the implications of these claims for any individual. Indeed, for all that has been said so far, these points might have no implications for any individual agent at all. I take it that Pogge would find this conclusion unsatisfactory. In order to avoid it, we need some account 
for how (backward-looking) responsibility at the collective level traces back to the individual level. Pogge says little that would help us to address this issue. This should now seem like a major lacuna in his view. In the remainder of this article I shall argue that there is no obvious strategy for repairing it.

We might hope that French's account might provide us with some way out of this impasse. French is certainly concerned with questions about how the (backward-looking) responsibilities of individuals and corporate agents relate to one another. However, the generality of French's account seems to preclude this possibility. In order for that account to function as a plausible account of corporate agency, it needs to be compatible with a wide range of models of corporate governance. However, it seems highly plausible that the details of how-if at all—backward-looking responsibility should distribute from the corporate to the individual level will depend on the details of the model that is operative in any given case. For example, we would expect such responsibility to distribute differently in a worker-owned co-operative in which each individual had considerable input into and knowledge of the projects being pursued by the corporation as a whole than in a corporation with a top-down management style in which employees had little input into decision making and little knowledge of what projects were being pursued. ${ }^{69}$

There is also a further reason for being pessimistic about the extent to which French's account of backward-looking collective responsibility might be one which would allow us to infer conclusions about backward-looking individual responsibility from claims about backward-looking collective responsibility. For French himself expresses doubts about the extent to which we are likely to be in possession of enough information to hold individuals responsible for their role in corporate decisions. ${ }^{70}$ And the problems seem to be magnified when we consider collectives which have collectives as their members, for we will need to be able to distribute responsibility from the individual to the collective level twice over. So even if we can say what "we" are responsible for in such cases, it may be impossible to determine what "I" am responsible for.

We might try to mitigate the seriousness of these conclusions. ${ }^{71}$ One possible response would be to say that what we have here is a purely epistemic problem: namely, that although individuals can know that they are responsible for playing some role in a collective rights violation, they cannot know precisely what they personally are responsible for. But the problem is more serious than this suggests. For it is typically the case that corporate responsibility does not distribute to all the members of a corporation which bears responsibility. On the other hand, Pogge's rhetorical stance, and many of his explicit statements clearly suggest that he takes it to be the case that many or all of the members of his "we" will be individuals to whom responsibility does distribute. ${ }^{72}$ As things stand that conclusion does not seem justified.

A second response might be to abandon the attempt to attribute responsibility to individuals, and restrict ourselves to a position on which we attribute responsibility to a group of collective agents, such as nations and multinational 
corporations. Even this might turn out to run into the same kinds of problems as beset the attempt to attribute responsibility to individuals. But it is also worth noting that this approach would involve abandoning Pogge's first-personal approach: it would leave us with an account on which the addressees of the conclusions of Pogge's arguments would be collective agents rather than individuals. I suspect that Pogge would not regard this as a friendly amendment to his view.

\section{Action-Guiding Implications for Individuals (2): Kutzian Accountability}

I noted in Section II that a fully convincing defense of Pogge's position would requires us to be able to explain how the truth of $\mathrm{N}$ might have actionguiding implications for particular individuals who form part of Pogge's "we." In Sections VIII-X, I argued that N1, N2, and R were best understood as involving nondistributive forms of predication, and in Sections XI and XII I explained why this raised difficulties for the project of deriving such action-guiding implications, and argued that a corporatist model of collective action does not help to circumvent these difficulties. We might, however, think that Christopher Kutz's work on individual accountability for collective action, which I mentioned briefly in Section III, offers an alternative and potentially more fruitful way forward. In the remainder of this article I shall argue that it does not.

Before doing so, it is necessary to address two obvious worries about this approach. The first is that, as I noted in Section III, Kutz's notion of accountability seems to be importantly different from that of either forward-looking or backward-looking responsibility. Second, we might worry about whether and how far the conclusions that Kutz comes to about accountability depend on his views about collective action. Since I have relied on an account of collective action that is different from Kutz's, we might worry that the approach he puts forward is one that is not available to us within the present argumentative context.

The fact that accountability is not the same as either forward- or backwardlooking responsibility turns out to be less of a drawback than it might at first seem. In Section III, I suggested that we should be concerned about backwardlooking responsibility because attributions of backward-looking responsibility could, in conjunction with the Natural View, support attributions of forwardlooking responsibility. It is this line of thought that led us to look, albeit unsuccessfully, for ways of deriving claims about individual backward-looking responsibility from claims about collective responsibility in Section XII. In conjunction with the Natural View about the relationship between backward- and forward-looking responsibility, such claims would give rise to action-guiding considerations for individuals. But one initially attractive aspect of Kutz's notion of accountability is that it suggests an alternative way of deriving actionguiding consequences which does not rely either on the Natural View or on our 
being able to make attributions of backward-looking responsibilities to individuals.

The worry that we may here be relying on a notion of collective action to which we should not be appealing in this context is also easily addressed. In discussing Kutz's account of collective action, I noted that, given his account of collective action, we could not plausibly infer that "we" were violating the rights of the worst-off from the claim that we were upholding the global economic order. However, I did not argue that Kutz's theory of collective action was itself incorrect. Furthermore, the possibility of a pluralist account of collective action leaves open the possibility that what counts as collective action under French's model will also count as such on Kutz's model (and in fact, Kutz thinks that this is the case. $)^{73}$ If we can identify principles on which we might hold individuals accountable for their role in collective action which do not depend on the claim that in so doing they are violating a right, we may still be able to apply them in this context.

Kutz puts forward two different tests for individuals' accountability for collective action. One is based on the maxims involved in collective action, and one based on the consequences of such action. On the face of it, either might provide for a way of deriving conclusions about the implications of the truth of nondistributive readings of N1, N2, and R for individuals. But I shall argue that neither of them does so. The maxim-based test does not do because, on this test, we are not accountable for our participation in the global economic order. And the consequence-based test does not do because the version of the test that Kutz puts forward is flawed. Although these flaws can be repaired, the repaired version of the test is one on which, once more, we turn out not to be accountable for our participation in the global economic order.

\section{Kutz's Maxim-Based Test}

I start by considering Kutz's maxim-based test. Kantians hold that it is impermissible - a violation of a negative duty-for individuals to engage in actions which have maxims which are not universalizable. Kutz's proposal resembles this Kantian principle but differs from it in two significant respects. It claims that individuals should be held accountable when they participate in collective projects that involve maxims that would fail Kantian-style tests of universalizability. This is significant for the following reason: it is at least possible, on Kutz's view, that the maxim which governs the actions by which I participate in some collective project should pass the universalizability test, but the maxim of the project as a whole should not. This will happen, for example, when an individual's contribution to the harm produced by the project is either marginal or pre-empted by others. ${ }^{74}$

I shall now argue that insofar as it is clear how to apply the maxim-based test, there is no reason to think that individuals who are part of Kutz's "we" fail it on the basis of their participation in the global economic order. Since the 
maxim-based test is only one of the tests for accountability that Kutz proposes, it does not follow that individuals who participate in upholding the global economic order cannot be held accountable at all. Participants in such projects may still be accountable under the consequence-based test that I discuss in Section XV.

I shall start by defending the view that although the maxims involved in collective projects need not be identifiable with the maxims of individual agents, facts about these maxims must be in some sense grounded in, and bear an intelligible relationship to facts about the maxims of such agents. I start with some observation about the notoriously controversial Kantian term "maxim." The following points are widely agreed among Kant scholars. First, maxims are rules or policies by which agents may guide themselves. Second, the fact that a certain policy or rule is not consciously present to one's mind when one decides what to do need not prevent it from being the maxim of one's action (indeed Kant often emphasizes the difficulties we might have in discerning the maxim under which we are acting). Third, it is not sufficient for something to be the maxim of one's action that it should correctly describe the way that one in fact acts: there are many such correct descriptions which are not the maxim of my action (I take this to be at least part of the point of Kant's discussion of the honest shopkeeper in Section II of the Groundwork of the Metaphysic of Morals.)

A more controversial, yet nevertheless defensible condition on something's being the maxim of my action is that the maxim of my action must be capable of playing a role in explaining how I act. It is a condition of its so doing that it be capable of entering into a rationalizing explanation both of the way in which I acted and of ways in which I would have (actually) acted if different circumstances had presented themselves to me. ${ }^{75}$

Suppose we take Kutz to be committed to the principle that something can only count as a maxim involved in a collective project if it can play a role in giving rationalizing explanations of actions that individuals take in pursuing that project. This constraint accommodates many of the kinds of cases that Kutz wants to accommodate, such as the case where an individual carries out a part in a plan, without that plan being fully transparent to them. For example, Kutz seems to hold that if I participate in a collective action such as the firebombing of Dresden, aspects of the plan that the instigators of the bombing had which may have been unknown to me are relevant to assessing my accountability. In such cases these maxims will play a role in explaining what I did. They will also be grounded in facts about the psychology of some individual agent. And in fact, given Kutz's commitment to a minimalist metaphysics on which there are no collective agents, it is hard to see how anything could play this kind of explanatory role without being grounded in the psychology of some agent or agents.

I conclude that the constraint that maxims should be grounded in the psychological states of agents is an appropriate one to apply when applying Kutz's maxim-based test. So understood, the maxim-based tests seem to provide no 
basis for a defense of N2. There seems to be no obvious maxim involved in either our economic participation in the global economy or our political participation in states which enforce the global order which meets the test of rationalizing explanatory relevance, and which would fail the universalizability test. I do not want to rule out the possibility that there might be some such maxim; but it is not clear to me what it might be.

We might think that a version of a maxim-based test that requires that maxims have some form of psychological reality is insufficiently demanding. One might, for example, take the profoundly un-Kantian view that something should count as the maxim of one's action provided it correctly describes all of one's actual actions. However, a version of the maxim-based test that leaves maxims unconstrained in this way seems impossibly demanding. For, however I act, there is likely to be some policy which is consistent with all of my actions in actual cases but which demands obviously unacceptable courses of action in cases which I do not encounter. A maxim of this sort will presumably fail Kutz's version of the universalizability test. But the mere possibility of such a policy, floating free of any causal or explanatory connection with what actually happens, shouldn't put me morally on the hook. While I take this point to be so obvious as to require no detailed defense, it is probably worth noticing that a principle which assigned accountability along the lines suggested would be so demanding as to be reasonably rejectable by those to whom it might apply under any plausible account of reasonableness. ${ }^{76}$

\section{Kutz's Consequence-Based Test}

Kutz's consequence-based test allows us to hold people accountable for participation in projects that do not involve the kind of explicit planning which seems required for the application of the maxim-based test. ${ }^{77}$ The test holds us responsible for the consequences of projects that we have participatory intentions to join in. I shall now try to show that the arguments Kutz puts forward in defense of this test should instead be taken to support a narrower view of accountability, and that on this narrower view it is implausible that we are accountable for violating the rights of the global poor.

Kutz defends his consequence-based test by reference to a small-scale example, involving a group of individuals all of whom participate in a picnic. Kutz argues that if one of these individuals, intending to play their part in the joint project of the picnic, carelessly places a rug over a neighbor's flower-bed, in such a way that the neighbor's flowers are damaged by it, all of the participants in the picnic, and not simply the ones who placed the rug or sat on it are accountable for the damage to the flower-bed.

However, even if we accept Kutz's claims about accountability in this particular case, the example underdetermines the principle involved. The example has at least three significant features, which might be taken to be relevant to assigning accountability, and which are lacking in other kinds of case of 
participation in a collective project. Two are relatively easy to understand. First, in the picnic case, the kind of damage for which individuals are being held accountable is reasonably foreseeable. Secondly, it is plausible that it is under the control of the picnickers, in the sense that there are alternative courses of action which would avoid damage to the flowers which are not only physically and psychologically possible, but also deliberatively accessible to the picnickers: that is to say, courses of action which they could and should have considered.

A third feature of the picnic example is slightly more complicated. Margaret Gilbert has suggested that the kind of collective action involved in the picnic example is of a type that might plausibly be taken to generate what Abraham Sesshu Roth has called "contralateral commitments.",78 Such commitments are generated by forms of collective action that make individuals answerable to one another for their performance. Gilbert has explored in detail a kind of collective action, involving joint commitment to a common project, on which it is highly plausible that such contralateral commitments arise. But, as she notes, on Kutz's account collective action need not involve joint commitment of this sort, and so need not give rise to contralateral commitments

We can see the potential relevance of these features of Kutz's example by considering a case in which they are lacking. Suppose I intend to participate, not in a genteel picnic, but as part of the audience at a rock festival. This will involve a participatory intention, so on Kutz's account it will involve collective action. ${ }^{79}$ However, on the face of it this does not seem to be the kind of collective project that generates contralateral commitments: if, having bought my ticket I decide not to go, I am not-typically-answerable to other audience members (matters may be different if I have arranged to go with a group of friends). Suppose further that although I am relatively responsible about what I do with my waste, and I try to make sure that others are as well, some of the other audience members dump their waste in a neighboring farmer's field. I shall simply stipulate that this is unforeseeable. ${ }^{80}$ Whether or not it is foreseeable, it does not seem to be under the control of the nonlittering members of the rock concert audience (although it may be under the control of the organizers).

It is far from clear that in this scenario I am accountable for the littering of other audience members, purely in virtue of being an audience member myself (matters may be different if I am an organizer of the concert). Furthermore, it seems plausible that my participation in the global economy has more in common with my participation in a rock concert than it does with my participation in a picnic. In particular, it seems plausible that even where the condition of foreseeability is met, the conditions of control and mutual answerability are not. We might wonder what to say about cases where one or two of the features involved are lacking but not the other. However, it is harder than one might think to pull all three features apart: in particular, contralateral commitment seems one plausible explanation of how control, as distinct from foreseeability, might be achieved. Nevertheless, it seems as though, if either control or contra- 
lateral commitment is necessary for accountability then my participation in the global economy will not be sufficient to make me liable.

Consider control first of all. Assume, optimistically, that there are economic arrangements that would result in better outcomes than those we have today, and that under those arrangements fewer or even none of the individuals whose rights are currently unfulfilled would go unfulfilled. It does not follow that from the fact that those arrangements are possible, and that we could act in ways that could bring them about, that the fact that we don't have those arrangements is a matter that is under our control. For, we might plausibly think that even if such arrangements are possible, they are not, as matters now stand, deliberatively available: it is simply not clear how we might get there from here.

Some might suggest that instead of considering control we should consider contralateral commitment. In particular they might claim that citizenship of a state involves precisely the kind of contralateral commitments to other citizens that Gilbert takes to be important here, and that via the capacity to vote individuals have control over the economic and diplomatic policies that their states pursue. ${ }^{81}$ This may be correct. However, it is not relevant to the current issue. For the question to be considered was not whether, as a citizen of a state, I am accountable for the policies of my state, but whether, as a member of a global agent consisting of a collective of collectives I am accountable for what that higher-level collective does. It is not clear how or whether the fact that I am a member of a state could give me contralateral responsibilities to citizens of other states. So again, the argument fails to support any plausible view about what individuals might be liable for.

\section{Avoiding Gaps in Accountability while Allowing Gaps in Responsibility}

I have argued that Kutz's principle for assigning accountability for the consequences of collective action is implausible; and that the more plausible principle which his argument supports is one which would not make individual members of Pogge's "we" accountable for the consequences of upholding the global economic order. But we might defend the original principle on the grounds that, unlike the revised principle, it avoids the unpalatable consequence that in cases of massive overdetermination of harm (such as the example he gives of the Dresden firebombing), no one is accountable.

We might not agree. First of all, it seems plausible that in many such cases the maxim-based test will be enough to establish accountability. Second, it is not clear that, in cases where harm is overdetermined, either the control condition or the contralateral commitment condition in the revised principle must fail. It is certainly not clear that they do in the Dresden firebombing case: we might think that in that case an alternative course of action, namely that of a general refusal to participate, was deliberatively available, and that the joint project is very much one of the kind that generates contralateral commitments. 
But suppose the objection was correct: how bad would the consequences be? That will depend on which of the two strategies I identified in Section X as ways of bridging the gap between accountability and liability we adopt. One approach was to forget about individual responsibility, and focus on accountability. Doing so would require us to give up on the Natural View about the relationship between backward- and forward-looking responsibility. But it would require more than this: it would require us to give up on any view on which individual backward-looking responsibility plays a significant role in determining forward-looking responsibility. Furthermore, it seems any such view could only retain the first-personal component that I argued to be an important component of Pogge's position, at the expense of making backward-looking claims like the Negative Duty claim play a relatively insignificant part in determining individual accountability.

The alternative strategy was to take the arguments Kutz put forward to be arguments in favor of principles of backward-looking responsibility rather than principles of accountability. If we adopt this strategy we will have to accept that some cases of overdetermined harm will give rise to backward-looking responsibility gaps at an individual level (though not at a collective level.) ${ }^{82}$ We might worry that, if we are committed to the Natural View of the relationship between backward- and forward-looking responsibility, responsibility gaps will give rise to gaps in forward-looking responsibility.

Gaps of this latter sort may be less acceptable. However, we will only be compelled to this conclusion if we accept not just the Natural View of the relationship between backward- and forward-looking responsibility, but also a stronger view on which backward-looking responsibility is the only possible ground for forward-looking responsibility. However this stronger view is implausible: backward-looking responsibility is only one of many bases on which forwardlooking responsibility might be assigned. ${ }^{83}$

\section{Concluding Remarks}

I have argued that we should adopt the "collective action" reading of Pogge's claim that we are upholding the global economic order and that we should do so on both textual grounds and grounds of philosophical fruitfulness. On this reading, we can make a good case for the truth of Pogge's claim, and for the further claim that we are violating a negative duty. French's account helps us to see how we might do so. However, I have also argued that the normative relevance of this fact to individuals is much less than we might initially be inclined to think. We could avoid this conclusion if we were able to articulate and defend a plausible view about the normative relevance for individuals of claims about collective responsibility. Pogge and those inspired by his moral vision have not yet suggested how we might do so: they should direct their efforts to this end. 
This article has taken a while to become publishable. I would like to thank Thomas Pogge, Frank Hindriks, Elizabeth Ashford, Felix Pinkert, Leonie Smith, Keziban Der, Sandrine Berges, Lucas Thorpe, Mark Steen; audiences at Collective Intentionality VIII (in Manchester) and at a Workshop on Plurals at Bogazici University in 2012 for helpful and illuminating discussion of earlier drafts; and two referees for this journal for their helpful and detailed comments on two earlier and shorter versions of the article from which I have learnt a great deal.

\section{Notes}

${ }^{1}$ Pogge $(2005,2007,2008,2010,2011,2013,2014)$. As one referee noted, Pogge's main focus in these works has been on violations of the right to life.

${ }^{2}$ O’Neill (1986); Shue (1996); Wringe (2005).

${ }^{3}$ Pogge $(2011,16)$.

${ }^{4}$ Pogge stresses the first-personal nature of his position in Pogge (2013, 311-12), and gives a particularly clear statement in Pogge $(2014,79)$. However, none of the extensive secondary literature on Pogge's work seems to address this feature of his position: it is not mentioned, for example, in any of the contributions other than Pogge's own to Pogge (2007), Jaggar (2010), or Brock (2013).

${ }^{5}$ See for example Pogge $(2011,3)$ : "what matters is the judgment each of us reaches about ourselves" (my italics).

${ }^{6}$ I discuss this further in Section II.

${ }^{7}$ Two recent exceptions are worth noting: Arneson (2013) and Reich (2014). Both assume that the collective agency version of Pogge's view can be defended, but do not address the question of how this might be done. Meckled-Garcia (2014) is an apparent exception since he cites Kutz's (2000a) book on complicity in collective wrongdoing fairly extensively. However, MeckledGarcia is mostly interested in ways in which individuals can be complicit in the actions of collective agents rather than in defending the claim that collective agents are guilty of rights violations or explaining how this can be so (something he seems to take more or less for granted). One way in which my view differs from Meckled-Garcia's in this article is that he does not countenance the possibility of nondistributive readings of $\mathrm{N} 1, \mathrm{~N} 2$, and $\mathrm{R}$, something that is central to my approach (I am grateful to an anonymous referee for drawing my attention to Meckled-Garcia's views and for extensive and textually detailed discussion of them, the results of which are reflected not only in this footnote, but also in sections II-VI, VIII, X, and XI of this article, and perhaps elsewhere.)

${ }^{8}$ Pogge himself says something similar: "moral prescriptions about what criteria rules and practices ought to meet must ultimately be cashed out as moral prescriptions addressed to human agents" $(2013,304)$.

${ }^{9}$ Even though this is not obvious, since one might think that the "we" that Pogge is addressing is too inchoate to count as an institution (I thank a referee for this journal for a comment that drew my attention to this point.)

${ }^{10}$ For an earlier discussion of some of the issues that arise here see Satz (2005) and Pogge (2005).

${ }^{11}$ Pogge $(2011,2-3)$. I thank an anonymous referee for drawing my attention to this passage.

${ }^{12}$ I am not entirely sure how Pogge (2011) intends us to take the phrase "suspend judgment" here, but I take it to mean that his view leaves the question open.

${ }^{13}$ Pogge (2011).

${ }^{14}$ The distinction I am making here corresponds closely to a distinction that Timothy M. Scanlon makes between what he calls "moral" and "substantive" responsibility, with Scanlon's "moral responsibility" corresponding to what I am calling "backward-looking responsibility," and what 
I am calling "forward-looking responsibility" corresponding to what he calls "substantive responsibility" (Scanlon 1998). I prefer the relatively colorless terms "backward-looking" and "forward-looking" for two reasons. First, both forward- and backward-looking responsibilities are appropriately described as "moral" in some fairly noncontentious understandings of the word "moral" (a sense which would allow us to distinguish between moral responsibilities and say, legal responsibilities, or those imposed by a tradition-based code of family responsibilities) in a way which Scanlon's terminology risks obscuring. Second, the backward-/forward-looking distinction is already fairly strongly embedded in the literature on collective obligation on which I draw heavily in what follows (see e.g., French 2014; Wringe 2014; 2016). I should also note that it is fairly common in the literature to assume there's a strong connection between backward-looking responsibility and the appropriateness of praise and blame (see in particular Pettit 2007 for a prominent example in the literature on collective obligations). But since praise and blame are themselves complex topics, and nothing in my argument depends on claims about them, I avoid explicit reference to them as far as possible in what follows. I also note, as a final point of clarification, that both forward- and backward-looking responsibility should be further distinguished from Scanlon's causal responsibility; I take this to be implicit in my discussion of the distinction between "causal contribution" and "collective agency" readings of Pogge's position in Sections IV ff

${ }^{15}$ Notably in Pogge (2011,31-32).

${ }^{16}$ Ibid.

${ }^{17} \mathrm{I}$ am grateful to an anonymous referee for making clear to me the need to specify the direction of explanatory priority required by the Natural View.

${ }^{18}$ The dubiously coherent view may strike many readers as so obviously untenable as to be unworthy of explicit mention, but occurred to a referee for this journal as a possible gloss on an earlier and less careful formulation of the Natural View.

${ }^{19}$ The Natural View is not the only possible view of the relationship between backward- and forward-looking responsibility. For an alternative, which has seemed attractive to some (see Young 2007; 2011; Ashford 2013, 144ff). So even if the 'Natural View' is false, it would not follow that the "we" who Pogge takes to be violating a negative duty are off the hook where forward-looking responsibility is concerned. I return to this issue in Sections XIII-XVI. My thanks to an anonymous referee for raising this issue, and to a further referee for drawing my attention to the importance of the illuminating discussion of the difference between Young's and Pogge's position in Meckled-Garcia (2014, 437-38).

${ }^{20}$ Kutz (2000a), passim. One might hold that Kutz's notion of accountability ties together forwardand backward-looking considerations in a way that is simply incoherent. It's not clear to me that this is true, but in any case I need to take no stand on this issue, since I shall argue in Sections XIVff that even if we allow it, it is of no help to Pogge.

${ }^{21}$ For example see Copp (2006) and Pettit (2007).

${ }^{22}$ Smiley and Oliver (2013).

${ }^{23}$ For ease of exposition, I omit reference to some of the qualifications of the Natural View mentioned in Section II.

${ }^{24}$ The 'Natural View,' for example, seems to support no such inference.

${ }^{25}$ Pogge $(2014,83)$ provides a rare exception. For reasons which will emerge in what follows, I think this is an unfortunate blunder.

${ }^{26}$ See Wringe (2016) for some suggestions as to how this second step might work in practice.

${ }^{27}$ One participant in the debate who does hold this view is Meckled-Garcia. See for example Meckled-Garcia $(2014,445)$.

${ }^{28}$ See for example French (1986); Gilbert (1989; 2008); Kutz (2000a; 2000b); List and Pettit (2011). One exception to the general rule is the notion of "aggregative collection action" found in Chant (2007). On this view, the N1ca collapses into N1cc. Since I argue that N1cc is not the best reading of Pogge's view, I don't discuss Chant's view in detail here.

${ }^{29}$ Kutz (2000a; 2000b).

${ }^{30}$ French (1986), passim. 
${ }^{31}$ Gilbert (2002).

${ }^{32}$ For example, we are told that the British state has an unsustainable national debt. By contrast, I myself have merely a modest overdraft.

${ }^{33}$ The distinction between the causal contribution and collective agency readings of N1 is, however, not obviously equivalent to the distinction between distributive and nondistributive readings of the plural predication that it contains; it is not clear that someone who makes a causal contributes to the global economic order's being upheld can themselves be described as upholding that order.

${ }^{34}$ Ashford (2013); Meckled-Garcia (2013). For an earlier discussion of a position rather like N1cc see also Ashford (2006). Elsewhere, Meckled-Garcia discusses (and argues against) a different interpretation of $\mathrm{N} 1$, on which individuals are complicit in the wrongdoing of collective agents; but this is also distinct from the view I discuss in this and following section since it does not involve any explicit commitment to nondistributive claims about either action or wrongdoing (Meckled-Garcia 2014).

${ }^{35}$ Parfit (1986).

${ }^{36}$ Further support for this reading might be found in Pogge's use of the term "collaboratively imposing" (Pogge 2011, 1).

${ }^{37}$ For further support for this reading of Pogge's position see Pogge (2013, 310-11).

${ }^{38}$ Pogge $(2005 ; 2007)$

${ }^{39}$ Lawford-Smith (2015).

${ }^{40}$ Meckled-Garcia (2013, 116-7).

${ }^{41}$ Ashford (2013) suggests that Meckled-Garcia may go wrong in assuming that rights violations must involve discrete actions by individual agents. On my understanding of Meckled-Garcia's view this seems inessential: there's no reason why we need to be able to tell which acts of a particular agent are the ones which unreasonably impose harm or risk: all we need to know is that there are some such acts. This could be true, for example, in a situation where I know that in exactly 50 percent of cases in which I press a certain button, some individual will have a fatal electric shock inflicted on them, even when I don't know exactly which cases these will be. What's important, presumably, is that there's some reasonable principle on which I don't press the button at all (Pogge seems to make a similar point in Concluding Reflections $(2013,307)$.

${ }^{42}$ This strategy is suggested in Ashford $(2013,140-41)$, although it is not clear whether she would subscribe to the particular conception of reasonableness that I have suggested as an alternative to Meckled-Garcia's.

${ }^{43}$ One qualm about this might be that it seems unreasonable to regard a particular individual as responsible for causing a particular harm if they could only have done so by adopting a principle that could have only reasonably been adopted if other agents had co-operated. But this need not count against the widened conception of reasonableness I have suggested. It might instead count as a reason for rejecting what, in Section II, I called the "Natural View" of the relationship between forward- and backward-looking responsibility. See, for example, Ashford (2013, 146-53).

${ }^{44}$ See for example French (1986); Gilbert (1989; 2008; 2013); Kutz (2000a; 2000b); Pettit (2007); List and Pettit (2011).

${ }^{45}$ For singularism see Kutz (2000b). For pluralism see Gilbert (2002).

${ }^{46}$ Although very little in my argument requires this, my sympathies are with pluralism.

${ }^{47}$ Kutz (2000a; 2000b) describes his account as a "minimalist" account of collective action. One might think that there is an even less demanding account of collective action available here than Kutz's-namely what Chant (2008) calls the "aggregative" conception of collective action, on which one participates in a collective action merely by virtue of making some causal contribution to a state of affairs to which others causally contribute. I ignore this conception of collective action here, since it is one on which N1ca turns out to be equivalent to N1cc.

${ }^{48}$ French (1986).

${ }^{49}$ I thank an anonymous referee for encouraging me to clarify this point.

${ }^{50}$ As I have already noted, while Pogge evinces some interest in the idea that we have forwardlooking obligations to remedy the harms caused by global poverty, he appears to ground these in 
duties to make good wrongs done. So we cannot skirt round the question of ascribing liability to individuals.

${ }^{51}$ Both examples are Kutz's own: see Kutz (2000a), $115 \mathrm{ff}$.

${ }^{52}$ Indeed, if as Kutz hints, such an analysis is impossible, this may be the best we can do in this context. But see Gilbert (2002) for serious objections to this suggestion.

${ }^{53}$ Kutz (2000a), passim; Kutz (2000b).

${ }^{54}$ Pogge has also indicated in conversation that he thinks this might be the right sort of account of corporate agency to adopt in this context; but as far as I know he has not explored this line of thought in print.

${ }^{55}$ French (1986). Note that French's views have changed in some important respects: see for example French (1995). However, one feature of his position that has remained more or less constant is a stress on what I earlier called "backward-looking" rather than "forward-looking" responsibility. For a critique see Hess 2014.

${ }^{56}$ French $(1986,39-41)$.

${ }^{57}$ French $(1986,43-47)$.

${ }^{58}$ As one referee pointed out, it's implausible to regard emotional identification as being relevant to questions about whether one is a member of a business corporation. I mention the point for two reasons. First, I think it does explain why there is some psychological resistance to using French's model of collective action. Second, even if the point is not relevant to the question of whether we are in fact members of such a corporation, it may nevertheless be relevant to whether the members of such a corporation can effectively address one another as "we."

${ }^{59}$ Stilz (2011).

${ }^{60}$ The question of whether the United Kingdom has an explicitly formulated corporate decision structure is distinct from the question of whether it has a written constitution. Whatever one thinks about the latter question, the fact that in the run-up to the general elections of 2010 and 2015 civil servants have needed to explicitly formulate procedures to be followed in the event of a hung Parliament suggests that the "corporate decision structure" of the UK had not been made fully explicit prior to those elections. Since there seems little reason to suppose that similar arrangements will not be needed in future, I take it that this remains true today.

${ }^{61}$ One obvious disanalogy between states and business corporations, noted by a referee for this journal, is that citizenship of a state is not always voluntary (though it can be in states where one can give up one's citizenship), whereas membership in a business corporation typically is. But it's not clear to me why this point should be relevant to determining whether the state is a collective agent with a decision-making procedure that allows for the possibility of attributing some actions of individuals to the collective agent. It is much more plausible to think that it is relevant to determining how different kinds of responsibility should be distributed from the collective agent to its members-an issue which I address in Section XI. For further discussion, see footnote 64.

${ }^{62}$ As one anonymous referee pointed out, it would be an exaggeration to see this as being true of international law as a whole: it may well not be true of those parts of international law which are based on custom and on related case law. But as the same referee conceded, it is plausible that it is true of treaty-based law. One might regard the point about customary international law as fatal here since, as the same referee has pointed out in subsequent discussion, the natural resource and sovereignty privileges on which Pogge bases much of his case might be viewed as part of customary rather than treaty-based international law (but see Schuppert 2014, 68ff for a discussion of ways in which treaty-based law also plays a significant role in this context of the resource privilege). Still, I think the point is less critical than the referee suggests: at best it suggests that, on the account I favor, the case for N1 would be better made by focusing on treaty-based aspects of the global economic order such as GATT (and it may not even show this, insofar as the effects of the natural resource privilege clearly could be modified by treaty-based measures either directly or indirectly in ways inspired by some of the suggestions made in Wenar 2008).

${ }^{63}$ Similarly, I don't think it undermines the position for which I am arguing in the article that the details of the decision structure of the international agent that plays a central role in my article 
are very different from those of most corporations, or that the roles that it defines don't correspond to those that are typical of a business corporation. The key point for my purposes is that we should be able identify such a structure in a way that makes it possible to distinguish between actions of that agent and actions of either individuals or nations.

${ }^{64}$ Wenar (2008); Schuppert (2014). I am grateful to my colleague Simon Wigley for drawing my attention to the relevance of Wenar's work in this context.

${ }^{65}$ Some discussions of so-called "Taurek" cases (Taurek 1977) such as that put forward in Timmermann (2004) seem to countenance this possibility.

${ }^{66}$ It is also a view which Meckled-Garcia himself rejects, since he concedes that states-which are presumably collective agents if anything is - can be complicit in rights violations (MeckledGarcia 2014, 445).

${ }^{67}$ David Copp defends this view in Copp (2007) and Copp (2009) as does Smith (2009). For dissent see Miller (2007); Ludwig (2007); Hindriks (2009); Collins (2017).

${ }^{68}$ Hindriks (2009); Collins (2017).

${ }^{69} \mathrm{We}$ might also expect the way in which any kind of responsibility distributed to be sensitive to the ways on which membership was a voluntary matter: for example, it would not be absurd to think the fact that one's membership of a collective body was involuntary might excuse one from a share in the responsibility one would otherwise bear for actions performed by that body. For further helpful discussion see Pasternak $(2011 ; 2013)$.

${ }^{70}$ French $(1986,138-39)$.

${ }^{71} \mathrm{I}$ am grateful to a referee for suggesting the responses considered in the next two paragraphs.

${ }^{72}$ Consider, for example, the quotation from Pogge $(2011,16)$ previously cited in footnote 3.

${ }^{73}$ Kutz (2000b).

${ }^{74}$ Although on some accounts of collective agency we could regard a maxim as being involved in a collective project if it is the maxim of some collective agent carrying out that project, Kutz's account should not be interpreted in this way. His account is intended to allow for the possibility of collective agency while avoiding any commitment to the existence of collective agents.

${ }^{75}$ Kant's commitment to transcendental idealism would, I take it, hold that the explanatory relationship here involves some kind of noncausal grounding - a notion that we should clearly not saddle Kutz with.

${ }^{76}$ In Section VI, I argued that the notion of reasonableness cannot bear a great deal of dialectical weight. Is it inconsistent of me to rely on it here? I don't think so: it's quite plausible to think that there isn't a clear way of choosing between the conceptions of reasonableness that Ashford and Meckled-Garcia offer, but that on any plausible conception of reasonableness the constraint imposed by the very loose conception of maxim will be unreasonably demanding.

${ }^{77} \mathrm{Kutz}(2000 \mathrm{a}, 140 \mathrm{ff})$.

${ }^{78}$ Roth (2004).

${ }^{79}$ This will be so even if we choose to characterize my involvement here as "attending" rather than "participating"; clearly what I intend is to take part in a collective enterprise.

${ }^{80}$ If it makes the stipulation seem more plausible, we can assume that the rock concert takes place in, say, Sweden, rather than the United States.

${ }^{81}$ Gilbert (2008).

${ }^{82}$ Some authors have been willing to accept views of this sort in the slightly different context of corporate responsibility. See French $(1986,138-39)$. Pogge might find this unacceptable. Pogge $(2014,85)$ suggests that he does, but provides no argument for rejecting this view, unless an incredulous stare counts as an argument in this context.

${ }^{83}$ For two alternative views see Young $(2007 ; 2011)$ and Wringe $(2005 ; 2014)$.

\section{References}

Arneson, Richard. 2013. "Appendix C: Comments by Richard Arneson.” Yale Human Rights and Development Law Journal 17: 103-13. 
Ashford, Elizabeth. 2006. "The Inadequacy of Our Traditional Conception of the Duties Imposed by Human Rights." Canadian Journal of Law and Jurisprudence 19: 207-35.

—. 2013. "Severe Poverty as a Systemic Human Rights Violation." In Cosmopolitanism versus Non-Cosmopolitanism: Critiques, Defenses, Reconceptualizations, ed. Gillian Brock, 129-55. Oxford: Oxford University Press.

Brock, Gillian. 2013. Cosmopolitanism versus Non-Cosmopolitanism: Critiques, Defenses, Reconceptualizations. Oxford: Oxford University Press.

Chant, Sara L. 2007. "Unintentional Collective Action.” Philosophical Explorations 10: 245-56.

Collins, Stephanie. 2017. "Duties of Group Agents and Group Members.” Journal of Social Philosophy 48: 38-57.

Copp, David. 2006. "On the Agency of Certain Collective Entities: An Argument from 'Normative Autonomy'." Midwest Studies in Philosophy 30: 194-221.

. 2007. "The Collective Moral Autonomy Thesis.” Journal of Social Philosophy 38: 369-88.

. 2009. "The Collective Moral Autonomy Thesis: Reply to Ludwig and Miller." Journal of Social Philosophy 43: 78-95.

French, Peter. 1986. Collective and Corporate Responsibility. New York: Columbia University Press.

—. 1995. "Ethics and Agency Theory." Business Ethics Quarterly 5: 621-27.

French, Peter A., and Howard K. Wettstein, eds. 2014. Forward-Looking Collective Responsibility. Malden, MA: Wiley Blackwell.

Gilbert, Margaret. 1989. On Social Facts. London: Routledge.

- 2002. "Collective Wrong-Doing: Legal and Moral Responses." Social Theory and Practice 28: $167-87$.

- 2008. A Theory of Political Obligation: Membership, Commitment, and the Bounds of Society. New York: Oxford University Press.

- 2013. Joint Commitment: How We Make the Social World. New York: Oxford University Press.

Hess, Kendy. 2014. "The Free Will of Corporations (and Other Collectives).” Philosophical Studies 168: 241-60.

Hindriks, Frank. 2009. "Corporate Responsibility and Judgment Aggregation.” Economics and Philosophy 25: 161-77.

Jaggar, Alison. 2010. Thomas Pogge and His Critics. Cambridge: Polity Press.

Kutz, Christopher. 2000a. Complicity: Ethics and Law for a Collective Age. Cambridge: Cambridge University Press.

- 2000b. "Acting Together." Philosophy and Phenomenological Research 61: 1-31.

Lawford-Smith, Holly. 2015. "What 'We'?” Journal of Social Ontology 1: 225-50.

List, Christian, and Philip Pettit. 2011. Group Agency. New York: Oxford University Press.

Ludwig, Kirk. 2007. "The Argument from Normative Autonomy for Collective Agents." Journal of Social Philosophy 38: 410-27.

Meckled-Garcia, Saladin. 2013. "Is There Really a 'Global Human Rights Deficit': Consequentialist Liability and Cosmopolitan Alternatives." In Cosmopolitanism versus Non-Cosmopolitanism: Critiques, Defenses, Reconceptualizations, ed. Gillian Brock, 111-29. Oxford: Oxford University Press.

—. 2014. "Does the WTO Violate Human Rights (and Do I Help It)?” Political Studies 62: 43551.

Miller, Seamus. 2007. "Against the Collective Moral Autonomy Thesis.” Journal of Social Philosophy 38: 389-409.

O’Neill, Onora. 1986. "Hunger, Needs and Rights." In Problems of International Ethics, ed. Stephen Luper-Foy, 263-82. London: Westview Press.

Parfit, Derek. 1986. Reasons and Persons. Oxford: Oxford University Press.

Pasternak, Avia. 2011. "The Collective Responsibility of Democratic Publics." Canadian Journal of Philosophy 41: 99-123. 
2013. "Limiting States' Corporate Responsibility." Journal of Political Philosophy 21: 36181.

Pettit, Philip. 2007. "Responsibility Incorporated." Ethics 117: 171-201.

Pogge, Thomas. 2005. "Severe Poverty as a Violation of Negative Duties." Ethics and International Affairs 19: 55-83.

— 2007. "Severe Poverty as a Human Rights Violation." In Freedom from Poverty as a Human Right, ed. Thomas Pogge, 11-54. Oxford: Oxford University Press.

2008. World Poverty and Human Rights. Cambridge: Polity Press.

_ 2010. Politics as Usual: What Lies behind the Pro-Poor Rhetoric. Cambridge: Polity Press.

—. 2011. "Are We Violating the Human Rights of the World's Poor?" Yale Human Rights and Development Law Journal 14: 1-33.

_. 2013. "Concluding Reflections." In Cosmopolitanism versus Non-Cosmopolitanism: Critiques, Defenses, Reconceptualizations, ed. Gillian Brock, 291-320. Oxford: Oxford University Press.

—. 2014. "Are We Violating the Human Rights of the World's Poor? Responses to Four Critics." Yale Human Rights and Development Law Journal 17: 74-87.

Reich, Robert. 2014. "Appendix A: Comments by Robert Reich." Yale Human Rights and Development Law Journal 17: 92-98.

Roth, Abraham. 2004. "Shared Agency and Contralateral Commitments." Philosophical Review 113: 359-410.

Satz, Debra. 2005. "What Do We Owe the Global Poor?" Ethics and International Affairs 19: 47-54.

Scanlon, Timothy M. 1998. What We Owe to Each Other. Cambridge, MA: Harvard University Press.

Schuppert, Fabian. 2014. "Beyond the National Resource Privilege: Towards an International Court of the Environment." International Theory 6: 68-97.

Shue, Henry. 1996. Basic Rights: Subsistence, Affluence, and U.S. Foreign Policy. Princeton, NJ: Princeton University Press.

Smiley, Timothy, and Alex Oliver. 2013. Plural Logic. Oxford: Oxford University Press.

Smith, Thomas. 2009. "Non-Distributive Blameworthiness." Proceedings of the Aristotelian Society 109: 31-60.

Stilz, Anne. 2011. "Collective Responsibility and the State." Journal of Political Philosophy 19: 190-208.

Taurek, John. 1977. "Should the Numbers Count?" Philosophy and Public Affairs 6: 293-316.

Timmermann, Jens. 2004. "The Individualist Lottery: How People Count, but Not Their Numbers." Analysis 64: 106-12.

Wenar, Leif. 2008. "Property Rights and the Resource Curse." Philosophy and Public Affairs 36: 2-32.

Wringe, Bill. 2005. "Needs, Rights, and Collective Obligations." Royal Institute of Philosophy Supplement 57: 187-208.

—. 2014. "From Global Collective Obligations to Institutional Obligations." Midwest Studies in Philosophy 38: 171-86.

— 2016. "Collective Obligations: Their Existence, Their Explanatory Power, and Their Supervenience on the Obligations of Individuals." European Journal of Philosophy 24: 472-97.

Young, Iris Marion. 2007. "Responsibility, Social Connection, Labour." In Iris Marion Young, Global Challenges: War, Self-Determination, and Responsibility for Justice, 159-87. Cambridge: Polity Press.

2011. Responsibility for Justice. Oxford: Oxford University Press. 